\title{
DESAIN SISTEM MEKANIK PADA TRANSMISI MOTOR MATIK UNTUK KESELAMATAN PENGENDARA
}

\author{
S. Ariyono ${ }^{1, *}$, B. Supriyo ${ }^{2}$, B. Sumiyarso ${ }^{3}$, B. Cahyono ${ }^{3}$, D.R. Harahap ${ }^{4}$ \\ ${ }^{1}$ Direktur Polmanbabel, Bangka 33211 \\ ${ }^{2}$ Jurusan Teknik Elektronika, Polines, Semarang 50275 \\ ${ }^{3}$ Jurusan Teknik Mesin, Polines, Semarang 50275 \\ ${ }^{4}$ Jurusan Teknik Mesin, Polmanbabel, Bangka 33211 \\ "E-mail: sugeng@ @olman-babel.ac.id
}

\begin{abstract}
ABSTRAK
Pasar kendaraan di Indonesia terutama sepeda motor sangat besar diperkirakan pertumbuhan kendaran sepeda motor mencapai 6 juta pertahun. Dari angka tersebut lebih dari 50 persen didonminasi oleh motor matik dan pasar motor matik ini semakin tahun semakin meningkat jumlah penjualannya. Hal ini dikarenakan motor matik ini mudah untuk mengendarainya. Ada beberpa kelemahan dengan sistem transmisinya diantaranya adalah tidak ada engine break saat jalan menurun. Motor akan jalan ketika dalam keadaan hidup kemudian tekan gasnya. Penelitian ini membahas tentang desain sistem mekanik pada transmisi motor matik yang mampu mencegah dari kesalahan pemakaian atau prosedur yang menyebabkan terjadi kecelakaan. Untuk mencapai tujuan tersebut maka perlu dilakukan beberapa langkah diantarnya adalah mereview desain yang ada, menentukan sistem penggantinya, mendesain sistemnya, membuat dan mengujinya. Dari hasil percobaan maka diperoleh kesimpulan bahwa sistem transmisi matik dapat digantikan dengan sistem mekatronik dengan desain khusus pada mechanical linkage-nya.
\end{abstract}

Kata Kunci: Motor Matik; Transmisi Sabuk Karet; CVT; Transmsisi Mekatroni.

\begin{abstract}
The vehicle market in Indonesia, especially motorbikes is very large, it is estimated that the growth of motorbike vehicles will reach 6 million per year. Recently, more than 50 percent is dominated by automatic motorcycles and the market increase significantly. This is because automatic motorcycles can be easily ridden. There are some weaknesses with this transmission system, among them is there is no engine brake when the road is in downhill condition. The motor will easily run when the gas throttle is pressed. This paper discusses the design of a mechanical system on the automatic transmission that is able to prevent mistake on procedures that causes accidents. To achieve this goal, it is necessary to do several steps, including reviewing the existing design, determining the new system, designing the system, manufactured and testing. Experiment results shows that the current motorcycles automatic transmission system can be replaced with a mechatronic system with special linkage mechanism to control ratio change.
\end{abstract}

Keywords: Automatic Scooter; Rubber Belt Transmission; CVT; Mechatronic Transmission. 


\section{PENDAHULUAN}

Transmisi yang pertama dibuat adalah transmisi sabuk atau Continuously Variable Transmission (CVT) ketika pertama mesin bakar ditemukan. Karena bentuknya yang besar dan kemampuan torsinya rendah maka ditinggalkan. CVT telah ditemukan dalam otomotif dan penerapan industri seperti alat permesinan sejak awal abad ke 20. CVT adalah alat transmisi daya, dimana rasio kecepatan dapat divariasi terus-menerus diantara dua batasan [1]. Terdapat banyak jenis dari desain CVT, tiap desain memiliki karakteristik masing-masing, seperti Belt CVT, Spherical CVT [2], Hydrostatic CVT [3], E-CVT [4], Toroidal CVT [5], Power-Split CVT [6], Chain CVT, Milner CVT [7], Ball-Type Toroidal CVT [8], dan sebagainya. Bagaimanapun, dari semua itu, tipe rantai dan sabuk yang paling banyak digunakan dalam CVT di penerapan atomotif [9].

Oleh karena itu konsep CVT lebih banyak digunakan pada permesinan seperti mesin milling untuk mengatur kecepatan spindle.

\section{METODE PENELITIAN}

Secara umum Gambar skematik dari CVT terdiri pulley penggerak, pulley yang digerakkan dan sabuk seperti yang terlihat pada Gambar 1.

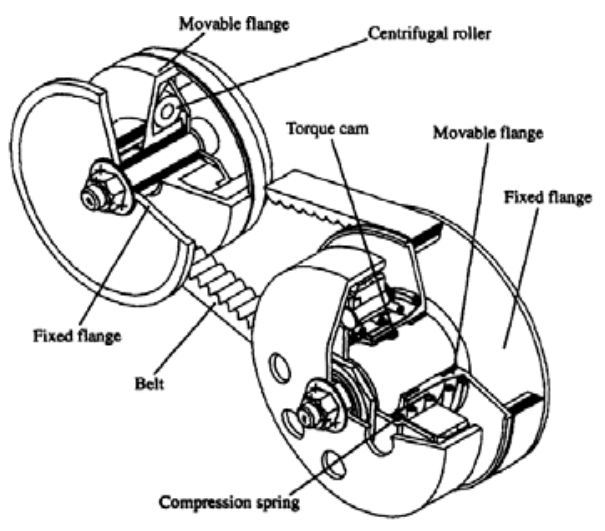

Gambar 1. CVT pada motor matik.

Secara ringkas cara kerja CVT tersebut adalah sebagai berikut:

a. Poros input tersambung langsung ke poros mesin sehingga bila mesin berputar cepat maka akan berdampak pada centrifugal roller. b. Perputaran poros mesin ini diteruskan ke pulley output melalui sabuk karet.

c. Pada pulley output terdapat kopling centrifugal yang bekerja ketika putaran mencukupi untuk memutar poros yang berhubungan dengan roda.

d. Perubahan rasio diakibatkan oleh gaya centrifugal roller akan mendorong moveble flange bergerak secara axial dan mendorong sabuk karet sehingga diameternya membesar. Sementara radius sabuk karet pada pulley output mengecil.

e. Sementara torque cam berfungsi pada saat kendaraan naik bukit. Cam ini akan berputar sehingga memaksa mendorong movable flange pada pulley output sehingga radius sabuk yang tadinya kecil akan membesar.

\subsection{Perhitungan Rasio Transmisi}

Untuk mendesain mekanisme yang mampu mengganti sistem mekanisme yang dipakai sekarang yaitu dengan sistem centrifugal maka konsep dasar perhitungan atau teori sabuk. Pada gambar 2 menunjukan skematik diagram pulley dan sabuk.

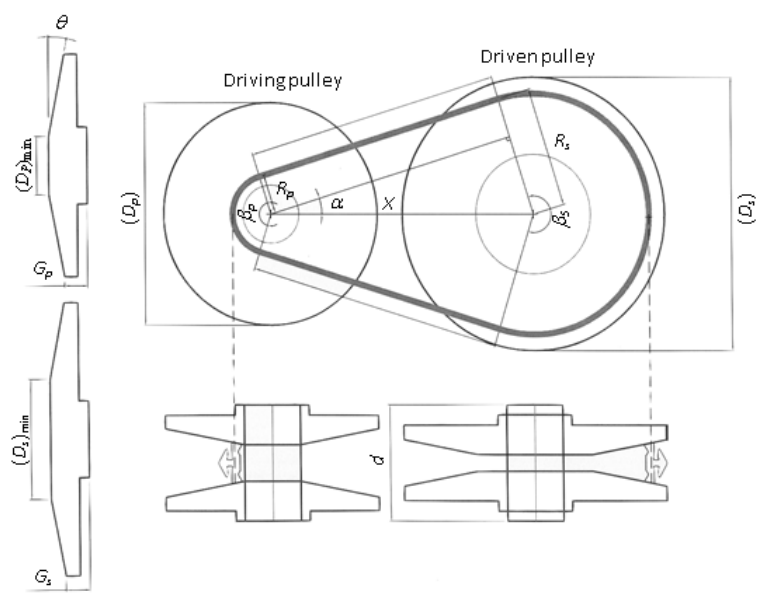

Gambar 2. Skematik diagram pulley dan sabuk

Notasi dalam skematik diagram tersebut adalah:

- X merupakan jarak poros pulley

- L merupakan panjang sabuk

- $\mathrm{R}_{\mathrm{p}}$ dan $\mathrm{R}_{\mathrm{s}}$ masing-masing adalah Radius pulley primer atau input dan Radius pulley sekunder atau output.

- $\theta$ adalah sudut kemiringan pulley 
Dari diagram skematik tersebut dapat diketahui panjang sabuk adalah:

$\left.\mathrm{L}=\mathrm{R}_{\mathrm{p}} \beta_{\mathrm{p}}+\mathrm{R}_{\mathrm{s}} \beta_{\mathrm{s}}+2 \sqrt{\mathrm{X}^{2} \quad\left(\mathrm{R}_{\mathrm{s}}\right.} \mathrm{R}_{\mathrm{p}}\right)^{2}$

Dimana: $\beta_{p}=\pi-2 \alpha$ dan $\beta_{s}=\pi+2 \alpha$

Perhitungan tersebut mengasumsikan bahwa tidak ada perpanjangan sabuk.

Sedangkan rasio dihitung berdasarkan perbedaan antara $R_{p}$ dan $R_{s}$.

Rasio trasnmisi $=\mathrm{R}_{\mathrm{p}} / \mathrm{R}_{\mathrm{s}}$

Dari persamaan di atas menunjukan bahwa perubahan rasio terhadap perubahan radius tidak linear.

Sedangkan sudut pulley $\theta$ digunakan untuk menghitung jarak pergeseran pulley (moveble flange) pada rasius $\mathrm{R}_{\mathrm{p}}$ tertentu. Jarak pergeseran moveble flange adalah $\mathrm{Rp} *$ Tan $\theta$. Setiap pergesaran moveble flange untuk menekan sabuk maka radius sabuk akan membesar sebanyak $\mathrm{Rp} * \operatorname{Tan} \theta$.

Dari hasil perhitungan tersebut ternyata perubahan atau pergerakan moveble flange terhadap rasio transmisi tidak linear. Gambar 3 menunjukan grafik antara perubahan axial moveble flange terhadap rasio transmisi.

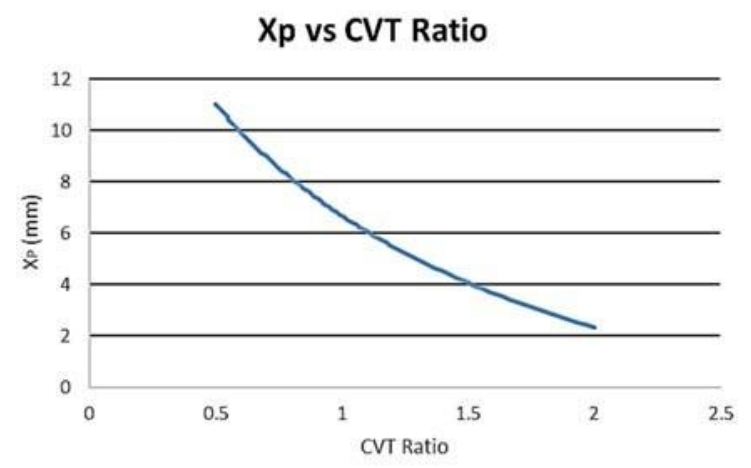

Gambar 3. Rasio vs pergerakan axial

\subsection{Desain Sistem Linkage Mechanism}

Sesuai dengan fungsinya bahwa transmisi digunakan untuk memindah kecepatan putar dan juga torsi dari mesin ke roda, maka transmisi harus mampu untuk mengubah rasio dari rasio rendah ke rasio yang lebih tinggi. Gambar 4 menunjukan sistem transmisi sabuk dari posisi rendah (low gear/under drive) ke posisi tinggi (high gear/over drive)

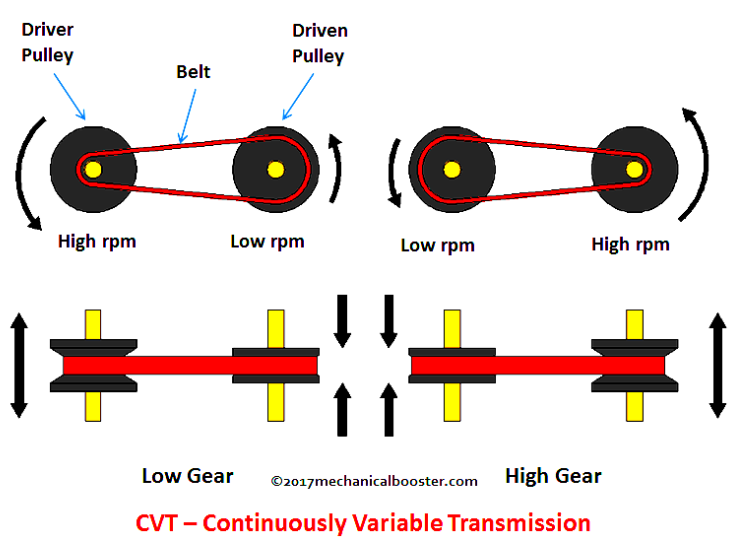

Gambar 4. Sistem CVT menggunakan sabuk karet (mechanical booster.com)

Pada trasnmisi sabuk karet yang dikontrol untuk berubah adalah pada sisi inputnya sedangkan untuk output-nya akan mengikuti.

Pada grafik digambar 4 menunjukan bahwa perubahan dari gear rendah ke gear tinggi memerlukan jarak sejauh $12 \mathrm{~mm}$.

Pada gambar 5 menujukkan salah satu alternatif untuk mengubah rasio dengan menggunakan cam.

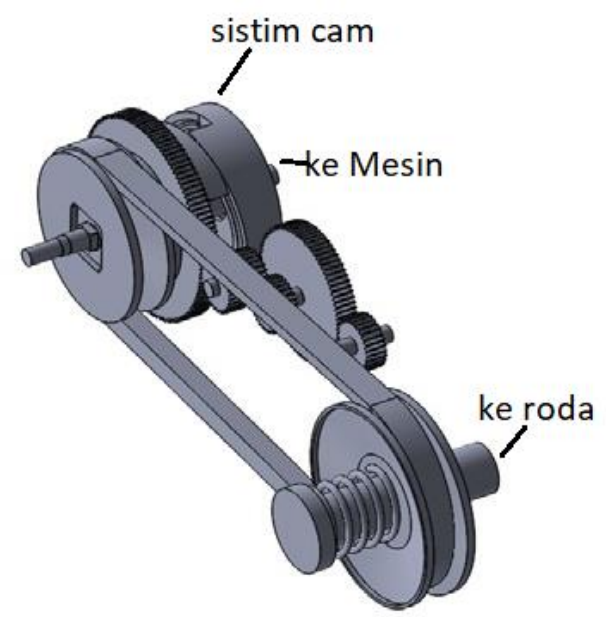

Gambar 5. EMSAPA-CVT

Sistem Elekto-Mechanics Single Acting Pulley Actuator Continuously Variable Transmission (EMSAPA-CVT) memasang motor sebagai penggerak pada Gambar 5. Sistem terdiri dari 2 pulley, yaitu pulley primer dan pulley sekunder. Motor menggerakkan pulley primer untuk perubahan rasio transmisi, sementara itu mekanisme pegas menggerakkan pulley sekunder untuk gaya apit [10]. Pegas digunakan pada pulley sekunder untuk mengurangi slip ketika perubahan rasio transmisi. 
Ketika CVT dalam posisi underdrive, radius primer sabuk minimum sedangkan radius belt sekunder maksimum, perubahan rasio terpanggil, motor primer akan menggerakkan pulley primer ke ukuran radius primer yang baru, dan pada waktu yang sama mekanisme pegas akan menggerakkan pulley sekunder untuk menghasilkan gaya apit optimal untuk mencegah slip sabuk [11]. Perpindahan tersebut akan berhenti ketika rasio yang diinginkan tercapai.

\section{HASIL DAN PEMBAHASAN}

Pada gambar 6 menunjukan model cam yang pernah didesain untuk digunakan sebagai pengubah rasio.

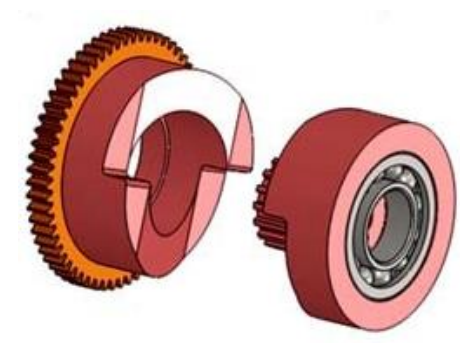

Gambar 6. Model cam versi

Konsep ini mampu mengubah rasio dari gear rendah ke gear tinggi hanya saja yang terjadi ketika cam berputar ada kontak titik ke titik yang pada awalnya kontaknya permukaan, sehingga kekuatan untuk menekan akan berkurang walaupun untuk sabuk karet kekuatan yang diperlukan untuk mengubah radius kecil tidak sebesar sabuk metal. Untuk mengatasi kekurangan tersebut maka didesain model baru seperti pada gambar 7 .

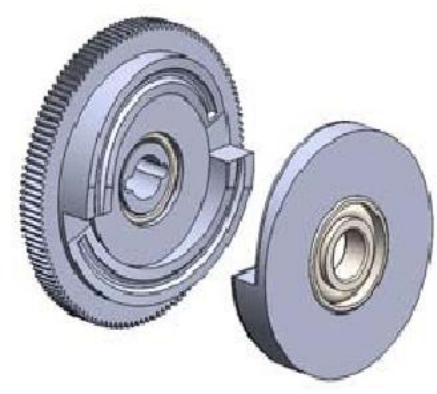

Gambar 7. Cam versi 2.
Konsep yang kedua ini jauh lebih baik dibandingkan dengan model pertama. Dari analisis komputer aliran gaya tekan lebih merata pada permukaan cam. Pada gambar 8 memperlihatkan pergerakan cam pada posisi yang berbeda dan terlihat bahwa pada setiap posisi permukaan cam akan kontak dengan cam lainnya secara rata.
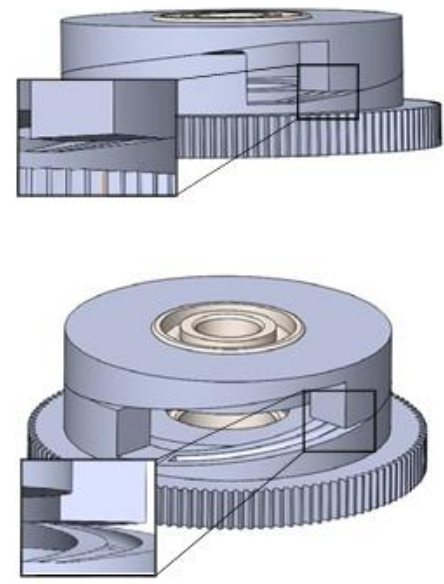

Gambar 8. Posisi kontak permukaan cam

Secara umum konsep yang terbaru ini mampu mengubah rasio dengan pembebanan pada permukaan cam secara merata.

Simulasi menggunakan software Solidworks untuk pembebanan sebsesar $1 \mathrm{kN}$ juga cukup aman dan tidak mencapai titik plastis walaupun dengan material sekelas alumunium.

Analisis cam dengan memberikan beban $1 \mathrm{kN}$ atau sebesar tegangan sabuk karet, karena pada analisis sebelumnya pada beban $20 \mathrm{kN}$ cam memasuki daerah plastis. Hasil anailsa pada beban $1 \mathrm{kN}$ dapat dilihat pada Gambar 9.

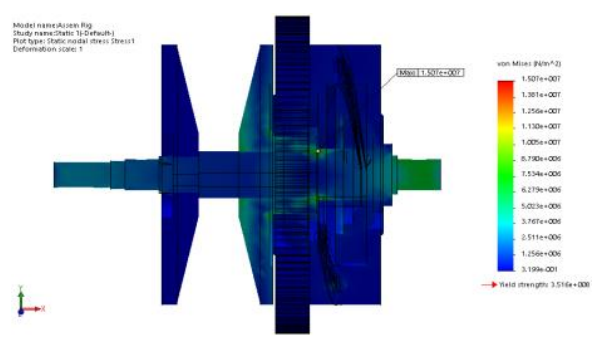

(a) 


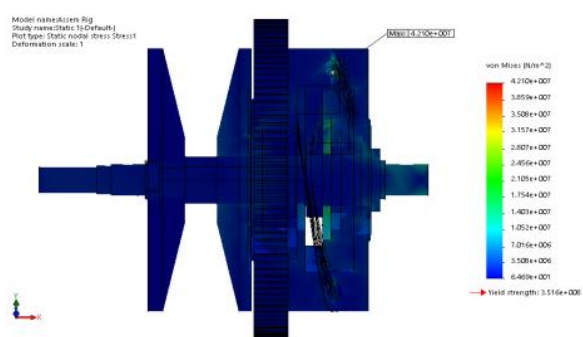

(b)

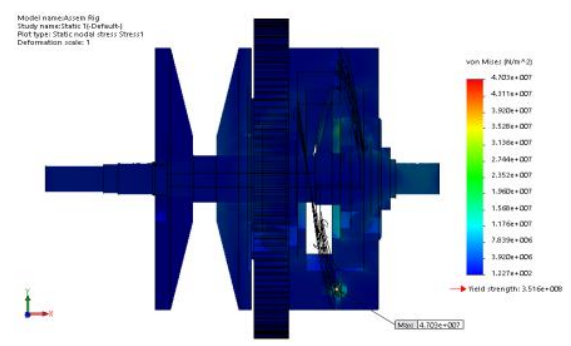

(c)

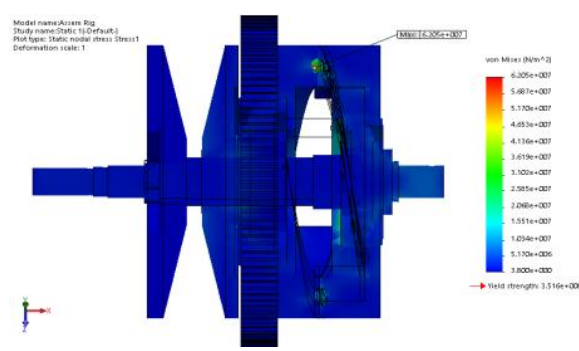

(d)

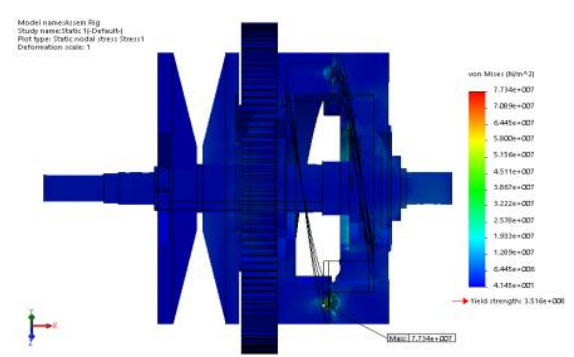

(e)

Gambar 9. Hasil simulasi cam dengan beban $1 \mathrm{kN}$ pada perpindahan pulley utama (a) $0 \mathrm{~mm}$ (b) $3 \mathrm{~mm}$ (c) $6 \mathrm{~mm}$ (d) $9 \mathrm{~mm}$ (e) $12 \mathrm{~mm}$

Gambar 9 (a) menunjukkan tegangan maksimal adalah $1,5 \times 10^{7} \mathrm{~N} / \mathrm{m}_{2}^{2}$ kemudian berturut-turut (b) $4,21 \times 10^{7} \mathrm{~N} / \mathrm{m}^{2}$, (c) $4,7 \times 10^{7} \mathrm{~N} / \mathrm{m}^{2}$, (d) $6,2 \times 10^{7} \mathrm{~N} / \mathrm{m}^{2}$ dan (e) $7,73 \times 10^{7} \mathrm{~N} / \mathrm{m}^{2}$. Analisis pada beban 1 $\mathrm{kN}$ masih berada dibawah tegangan yield, maka cam masih aman jika diberi beban 1 kN. Pada Gambar 9 (b), (c), (d) dan (e) tegangan maksimal berada pada ball bearing, sedangakan pada Gambar 9 (a) tegangan maksimal berada pada input shaft karena perpindahan pulley utama adalah $0 \mathrm{~mm}$.

Pada gambar 10 memperlihatkan konsep akhir EMSAP-CVT dengan dilengkapi control system. Konsep EMSAPA-CVT sebenarnya sangat mudah yaitu mengubah putaran menjadi gerak linear yang digunakan untuk mengganti centrifugal roller yang mendorong movable flange sehingga terjadi perubahan rasio pada transmisi. Mechanical linkage yang mampu melakukan berubahan tersebut diantarnya adalah cam yang dalam penelitian ini disebut sebagai surface cam atau cam permukaan. Perputaran cam permukaan menghasilkan gerakan linear sehingga putarannya dapat dikontrol yang menghasilkan gerakan linear yang juga terkontrol.

Pada gambar 10 tersebut gear reducer digunakan untuk mengurangi putaran karena pergerakan cam hanya $180^{\circ}$ untuk mendapatkan rasio dari rasio rendah ke rasio tertinggi. Dengan menggunakan motor yang mempunyai rpm rendah sehingga putaran camnya dapat dikontrol lebih presisi.

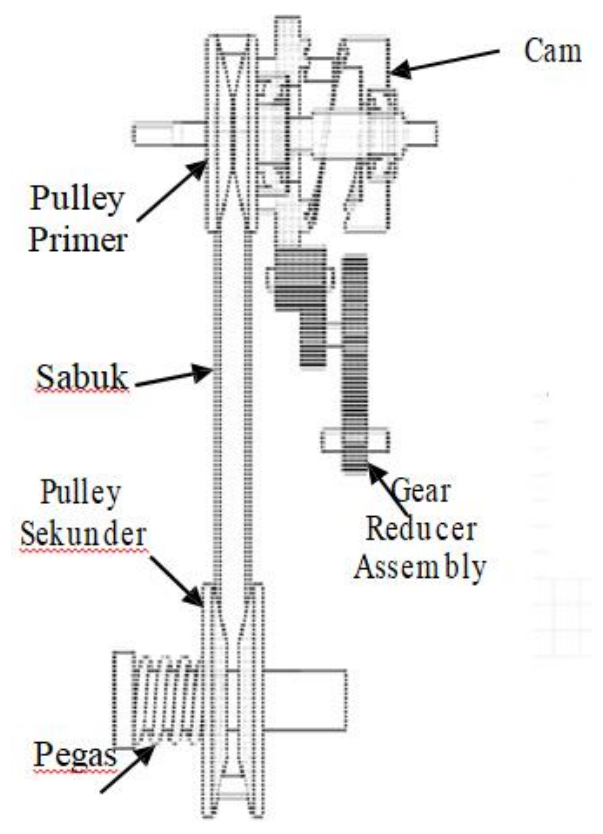

Gambar 10. Konsep akhir EMSAPA-CVT 


\section{KESIMPULAN}

Dapat disimpulkan desain baru dari cam permukaan dapat memperbesar area kontak ketika cam diputar, dimana meningkatkan kemampuan memberi gaya untuk menekan pulley berpindah secara aksial. Desain cam yang baru pada system EMSAPA-CVT juga dapat dikontrol dengan beberapa metode kontrol. Hasil analisis menunjukkan bahwa cam dapat menerima beban hingga sekitar 4 $\mathrm{kN}$, sehingga masih aman untuk digunakan pada sabuk karet. Cam masih dapat menerima beban sebesar $5 \mathrm{kN}$ jika dilakukan perubahan material pada ball bearing.

\section{DAFTAR PUSTAKA}

[1] Park, N.G., Ryu, J.H., Lee, H.W., Jeon, Y.H., and Zhang, N., Development of the inner spherical cvt for a motorcycle, International Journal Automotive Technology, 2009(3); 10: 341-346.

[2] Kim, J., Park, F.C., Park, Y., and Shizuo, M., Design and analysis of a spherical continuously variable transmission, ASME Journal of Mechanical Design, 2002; 124: 2129.

[3] Kanphet, P., Jirawattana, P., Direcksataporn, B., Optimal operation and control of a hydrostatic CVT powertrain, SAE Transactions Journal of Passenger Cars: Mechanical Systems, 2005; 114(6): 18381845.

[4] Miller, J.M., Hybrid electric vehicle propulsion system architectures of the e-CVT type. IEEE Transactions on Power Electronics, 2006; 21(3): 756-767.

[5] Fuchs, R., Hasuda, Y., and James, I., Modeling simulation and validation for the control development of a full-toroidal IVT, Proceedings of CVT 2002 Congress, 2002; 1709: 121-129.

[6] Mantriota, G., Theoretical and experimental study of a power split continuously variable transmission system, Part 2, Proceedings Instn. Mech. Engrs, 2001; 215(D): 851- 864.

[7] Milner, P.J., Milner CVT for high torque applications, Proceedings of CVT 2002 Congress, 2002; 1709: 543-554.

[8] Belfiore, N.P., Stefani, G.D., Ball toroidal CVT: a feasibility study based on topology, kinematics, statics and lubrication, International Journal of Vehicle Design. 2003; 23(3-4): 304-331.
[9] Zheng, C.H., Lim, W.S, and Cha, S.W., Performance optimization of CVT for twowheeled vehicles, International Journal of Automotive Technology, 2011; 12(3): 461-468.

[10] Mohd, E.Z., Kamarul, B.T., Hussein, Bambang, S., Aishah, D., Clamping force characteristic study of power screw mechanism in EMDAP, 3rd International Graduate Conference on Engineering, Science and Humanities IGCESH, 2010.

[11] Bambang, S., Kamarul, B.T., Hishamuddin, J., and Sugeng, A., Ratio Control of An Electromechanical Dual Acting Pulley Continuously Variable Transmission (EMDAP-CVT) System Using PD-Fuzzy Logic Controlle, Regional Postgraduate Conference on Engineering and Science (RPCES`06), 26-27 July, Johor Bahru Malaysia, 2006. 